\title{
Erratum to: An assessment study in the determination of chemical elements in sediments and fish in the Zarka River and King Talal Dam, Jordan
}

\author{
A. Alsabbagh ${ }^{1}$ (1) $\cdot$ L. Khalayleh $^{1} \cdot$ M. Dbissi ${ }^{1} \cdot$ S. Landsberger $^{2}$
}

Published online: 7 September 2017

(C) Akadémiai Kiadó, Budapest, Hungary 2017

Erratum to: J Radioanal Nucl Chem

DOI 10.1007/s10967-017-5355-2

The affiliation of the third author was incorrectly published in the original article. The author's correct affiliation appears in this erratum.

The online version of the original article can be found under doi:10.1007/s10967-017-5355-2.

\footnotetext{
A. Alsabbagh

ahalsabbagh@just.edu.jo

1 Department of Nuclear Engineering, Jordan University of Science and Technology, Irbid 22110, Jordan

2 Nuclear Engineering Teaching Laboratory, University of Texas at Austin, Austin, TX 78712, USA
} 